In Section 3, which follows a brief introductory section and a descriptive section on the general nature of the hazards, are given the present recommendations on maximum permissible levels of radiation for those occupationally exposed to radiation and for those working nearby; these are based on the Medical Research Council's evaluation of the recommendations of the International Commission on Radiological Protection. In addition to listing the levels for external radiation, examples are given of actual values of maximum permissible body burdens and maximum permissible concentrations in air and water.

There is a brief outline of the measurement of radiation dose and dose-rate in Section 4; monitoring for neutrons is outside the scope of the manual. Due consideration is given to the use and value of film dosimeters, but there is no mention of whether any film-badge service is generally available. In this section reference is made to the selection of radiological safety officers to ensure that protection measures in a particular department are carried out; and to the appointment of an appropriately qualified physicist as 'radiological protection adviser' to advise the head of each department. These officers are akin respectively to the departmental radiation supervisor and university radiation protection officer recommended in the recently published Code of Practice for the Protection of Persons exposed to Ionising Radiations in University Laboratories (The Association of Universities of the British Commonwealth, London, 1961). It is also pointed out in the manual that the radiological protection adviser should work in close association with a qualified medical adviser. These officers can also be compared with the "competent persons" in the Factories Acts Regulations whose duties are to "exercise special supervision with regard to the requirements of these Regulations and to assist in enforcing the observance of them". (Factories, The
Ionising Radiations (Sealed Sources) Regulations, 1961 (London, H.M.S.O., 1961); Ministry of Labour, Factories Acts, 1937-1959, Unsealed Sources Regulations, Preliminary Draft of Regulations (London, H.M.S.O., 1961).

Sections 5 and 6, on "Acceptable and Hazardous Amounts of Radioactive Material", contain a table classifying isotopes according to their relative radiotoxicity. This table is in line with the table in the first schedule of the Unsealed Sources Regulations. Laboratories are graded as $A, B$ or $C$ according to the quantity of radioactivity involved and its radiotoxicity; in addition, account is taken of the nature and complexity of the processes involved. This method of classification is the one that is most often given in codes of practice for safe handling of radioactive materials; however, it is not the only one, and practical experience has shown that other systems of classification of radiation and contamination give effective control of exposure to radiation.

The remaining sections of the manual cover protective clothing and devices; exhortations on 'do's' and 'don'ts' when handling radioisotopes; eating, smoking and washing; storage; a valuable section on disposal of radioactive wastes which takes account of what the situation will be when the Radioactive Substances Act, 1960, comes into force; and a final short section giving advice on where to apply for particulars concerning transport of radioisotopes.

The bibliography covers publications issued up to the end of 1960. In the field of radiological safety so much coding and regulation is in progress that there have been at least three major documents issued since the manual was published. With this accretion of regulations and advice the manual is invaluable for all those concerned with the use of radioactive substances and the control of health hazards as a handy summary of authoritative advice at a given point in time.

\title{
NEUTRON CAPTURE THERAPY
}

$\mathrm{N}$ EUTRON capture therapy is an experimental radiotherapeutic procedure involving new concepts in the treatment of cancer. This treatment is a means of achieving selective irradiation of a tumour tissue by inducing throughout that tissue radioactivity of high biological efficiency. The radioactivity is induced in situ by means of the capture of thermal neutrons by a suitable target element. To develop the most efficient system, a target element is chosen which, on thermal neutron capture, decays immediately through emission of energetic heavy particles such as $\alpha$-particles. Since the range of heavy particles of $2-4-\mathrm{MeV}$. energy in tissue is very short, of the order of less than $15 \mu$, the resulting radiation effects are limited to the region of origin. Because radioactive decay is practically instantaneous and results in a stable element, physiological dispersion from the origin is prevented. Only those elements which have a high thermal-neutron capture cross-section, such as boron-10, lithium-6, and uranium-235. are useful. This suggestion was first put forward in 1936 by Locher. The utilization of thermal neutron capture by boron-10 for the treatment of human-brain tumours, chiefly glioblastoma multiforme, has been under investigation at the Medical Research Center of Brookhaven National Laboratory, Now York, since 1949.
An account of the biological effectiveness of thermal neutrons and of heavy particles from the ${ }^{10} \mathrm{~B}(\mathbf{n}, \alpha)^{7} \mathrm{Li}$ reaction for the rabbit's ear and its utilization for neutron capture therapy has been given by Yaskazu Lucas Yamamoto (Yokohama Medical Bulletin, 12, No. 1, February 1961).

Throughout this series of cases, the pathological effects of thermal neutrons and of the heavy particles from the ${ }^{10} \mathrm{~B}(n, \alpha)^{7} \mathrm{Li}$ reaction on human skin occurring at the point of neutron entry have been known as one of the most vexing side-effects of neutron-capture therapy. Among other side-effects such as boron toxicity, radiation parotitis, and radiation conjunctivitis, it has particularly attracted the attention of investigators, and an effort has been made to prevent or reduce the complication. In reviewing the brain tumour cases treated by neutron-capture therapy at the Medical Research Center, Yamamoto and his co-workers have encountered varying degrees of skin reactions in a large percentage of the cases ranging from erythema to severe radiation dermatitis.

In a previous series of experiments on human brain tumours, attempts were made to decrease skin radiation by decreasing the boron concentration in the skin while maintaining a maximum concentration in the neoplastic tissue in the brain. The methods 
used were those of scalp pressure bandages, temporary bilateral ligation of external carotid arteries, and boron-10 infusion into the internal carotid artery on the same side as the tumour. These methods were not adequate in preventing severe reaction since a large neutron dose was required to treat a deep-lying tumour because the thermal neutrons attenuate rapidly in tissue.

A research project has therefore been undertaken to determine the minimal dose of thermal neutrons and of the heavy particles from ${ }^{10} \mathrm{~B}(\mathrm{n}, \alpha)^{7} \mathrm{Li}$ reaction to produce radiodermatitis on the ear of the rabbits, and to investigate the details and characteristics of skin reaction and their prevention, especially by the employment of neutron-shielding materials for medical use.

The findings show that the safe skin dose (no more than grade-2 skin reaction) of thermal neutrons and of the heavy particles from the ${ }^{10} \mathrm{~B}(\mathrm{n}, \alpha)^{7} \mathrm{Li}$ reaction on rabbits' ears are established to be less than
$10 \times 10^{12} \mathrm{n} / \mathrm{cm} .^{2}$ with thermal neutrons exposure alone and $1.5 \times 10^{12} \mathrm{n} / \mathrm{cm} .{ }^{2}$ with $35 \mathrm{mgm}$. ${ }^{10} \mathrm{~B}$ per $\mathrm{kgm}$. body-weight. A review of clinical data shows the maximum safe skin dose to be roughly $0.5 \times$ $10^{12} \mathrm{n} / \mathrm{cm} .{ }^{2}$ with $25-50 \mathrm{mgm}$. ${ }^{10} \mathrm{~B}$ per $\mathrm{kgm}$. bodyweight. These clinical data have been correlated with work on the differences of radiosensitivity between human beings and rabbits' ears by Ellinger.

The medical uses of neutron-shielding materials from both physical and biological points of view have been considered, and the utilization of the above data to avoid skin complications in neutron-capture therapy for human brain tumours is indicated by Yamamoto. The use of the temporary skin flap and lithium metal shielding has been successful in avoiding skin complications. The value of relative biological effectiveness is calculated to be $\mathbf{3 . 9}$ from thermal neutron exposure alone and to be 1.87 from neutron-capture therapy from the ${ }^{10} \mathrm{~B}(\mathrm{n}, \alpha)^{7} \mathrm{Li}$ reaction with $35 \mathrm{mgm}$. per $\mathrm{kgm}$. body-weight.

\section{LAND-USE SURVEY : NICARAGUA}

$I^{\mathrm{T}}$ is now well recognized that the world's agriculture must become more intensive if it is to keep pace with the increasing population of this planet. Earlier warnings by Lord Boyd-Orr can now only be accepted as fundamentally real, and have been placed in perspective by Dr. Norman Wright, deputy director of the Food and Agriculture Organization of the United Nations. He estimates that if agriculture makes use of all the technical assistance available, there is no reason why it cannot keep pace with the increasing demands for food, at least to the turn of this century. One of the first technical contributions to agricultural intensification of a country is a survey of the optimum uses of land, and the first parts of such a survey in Nicaragua have been published recently.

Nicaraguan agriculture is at present not very intensively developed. The latest returns (for 1952, in the Food and Agriculture Organization's Yearbook 13, 1959) show it to have a total area of $14,800,000$ hectares of which more than 26 per cent is built on or otherwise unusable. Of the productive area the largest proportion is forest ( 57.5 per cent). Pastures account for nearly 6 per cent and arable crops nearly 8 per cent, while 29 per cent is potentially productive, though not used at present. This should be a most rewarding setting for a land-use survey, shows particular foresight of the originators, and Dr. Taylor has indeed produced a report which demonstrates how Nicaragua could not only feed more than her own rapidly expanding population for some time to come but also maintain and increase the forestry assets*.

Grassland improvement is perhaps the most basic, for stock depends on it more than on arable crops. Enhanced grazing value of the savannah is possible by mowing or controlled burning, and on more fertile ground, the wasteful bush fallow should be replaced by a period of from four to six years of rotation pasture with controlled grazing by stock. There is,

* Republica de Nicaragua, C.A. Ministerio de Economia, Instituto de Fomento Nacional, y Organizacion de las Naciones Unidas para la Agricultura y Alimentacion. Estudios Ecologicos, Volumen No. 1 Agricultura y Alimentacion. Estudios Ecologicos, Volumen No. 1 (1959). Estudios Ecologicos para el Aprovechamiento de la Tierra en Nicaragua (Ecological Land Use Surveys in Nicaragua). Pp. Xv +338 . By Dr. B. W. Taylor. (Managua, D.N.: Ministerio de Economia, para la Agricultura y Alimentacion (F.A.O.), 1959.) however, urgent need to introduce more productive grasses and legumes.

Perhaps the greatest need for the survey is shown in forestry organization. In the Puerto Cabezas-Rio Coco area, the pine forests are only sufficient for a further seven years supply, yet the industry could be built up to have a perpetual annual income of at least 23,000,000 dollars (U.S.), and measures to effect the transition are discussed. On the other hand, in an area to the north of Santo Domingo, standing timber valued at approximately $100,000,000$ dollars (U.S.) is likely to be destroyed in the gradual clearing of land for agriculture and grazing. A project to utilize it is described. It is recommended that a small forest service concentrating on fire control be established, pasture and plant introduction officers be appointed and that there should be a small service for crop protection, for diseases and pests are severe in the condition of high rainfall.

Climate and soils in Nicaragua are very suitable for a considerable expansion of cash crops. Large areas would, for example, be suitable for growing rice, with or without low-lift irrigation, which could cover immense areas at low cost. The survey indeed leads to the conclusion that Nicaragua might well export rice, meat, milk, cheese, sugar, eitrus products, peanuts, beans and cacao. This raises one of the main difficulties of expanding world food production, namely, of adjusting increased production to new markets. Unplanned flooding of world markets would destroy the whole economies of production, and Dr. Taylor very rightly considers this aspect in addition to the detailed ecology of his valuable report. The population of Nicaragua, however, has increased from 765,000 in 1937 to $1,378,000$ in 1958 , so if this very rapid increase persists, the internal market alone will demand considerable expansion of food supply and resources.

The classic instances of Israel and Taiwan show what can be achieved by the planned use of land, and, in complimenting Nicaragua and the Food and Agriculture Organization on this progress, we look forward to the remaining parts of the survey and to the implementation of its recommendations.

JoHN GRAINGER 